\title{
A New Ion Pair-based Surfactant-assisted Dispersive Liquid-Liquid Microextraction of Ultratrace Levels of Beryllium From Natural and Effluent Samples Followed by ETAAS Determination
}

\author{
Noorbasha N. Meeravali*, K. Madhavi, and Sunil Jai Kumar \\ National Centre for Compositional Characterization of Materials (NCCCM), \\ Bhabha Atomic Research Centre, ECIL Post, Hyderabad-500 062, India
}

\section{INTRODUCTION}

Beryllium (Be) and its compounds have been identified as potential toxicants to living organisms $(1,2)$. They cause acute and chronic lung disease known as berylliosis $(3,4)$. Due to its unique properties, Be is used extensively in high-technology applications such as the aerospace and nuclear industries $(5,6)$. Furthermore, the levels of this metallic element have increased in the environment through combustion of coal and fuel oils. Various international guidelines restrict its maximum contaminant level in drinking water to $0.1 \mathrm{ng} \mathrm{mL}^{-1}$ (7). In order to prevent water and environmental contamination and at the same time to allow its use for high-technology applications, recycling of Be from anthropogenic sources becomes essential. This demands the development of a simple and fast analyte separation and selective pre-concentration procedure.

Over the last several years, various extraction procedures have been developed for separation and pre-concentration of beryllium from various water samples. Solid phase extraction using acetylacetone as a chelating agent and coprecipitation with hafnium hydroxide has been used most frequently $(8,9)$. Some researchers have used chrome azurol S/cupferron and 1,8-dihydroxyan-

\footnotetext{
Corresponding author.

E-mail: nnmeeravali29@ rediffmail.com Fax: +914027125463
}

\section{ABSTRACT}

A new ion pair-based surfactant-assisted dispersive liquidliquid microextraction (IP-SA-DLLME) procedure was developed for the separation and pre-concentration of ultratrace levels of beryllium from effluents and natural water samples. A cetylpyridinium ammonium bromide (CPAB) cationic surfactant was used as both ion pairing and dispersing solvent. The method is based on the formation of extractable hydrophobic ion pair complexes of an anionic specie of beryllium-oxalate with the cationic head group of $\mathrm{CPAB}$ dispersive aggregates in the presence of oxalic acid. Chloroform was used as an extracting solvent for the pre-concentration of the formed extractable ion pair from a bulk aqueous phase into a small chloroform phase at room temperature. This provides an energy-efficient extraction process and avoids the addition of an external chelating agent. The recoveries were in the range of $92-98 \%$ at $50-250 \mathrm{pg} \mathrm{mL}^{-1} \mathrm{Be}$, which would be impossible to achieve with conventional dispersive liquid-liquid microextraction. Several factors influencing the recovery were investigated and optimized for providing better recoveries. Under the optimized conditions, the pre-concentration factor was 25 and the limit of detection was $1 \mathrm{pg} \mathrm{mL} \mathrm{m}^{-1}$ The accuracy of the procedure was verified by ETAAS analysis of certified reference materials. The procedure was applied to effluent and natural water samples. throneas as chelating agents and extraction by using micelle and mixed micelles-based cloud point extraction (7, 10-13). Recently, hydroxybenzoquinoline fluorescent chelating agents immobilized in a silica nanopiller platform and silica gel-loaded column have been used for extraction of beryllium $(14,15)$. Nevertheless, these are time-consuming methods, and routine analysis is not possible.

Nowadays, dispersive liquidliquid microextraction (DLLME) has emerged as an efficient microextraction procedure for the separation and pre-concentration of a variety of uncharged hydrophobic species $(16,17)$. The greatest limitations are the low extraction efficiencies of hydrophilic inorganic/ organic species and polar organic compounds. This is mainly due to a low partition coefficient of these species into the extracting solvent in the presence of a conventional organic disperser (18). These limitations were overcome by the introduction of a new version of DLLME by Yousefi et al. in 2010 (18), referred to as surfactant-assisted dispersive liquid-liquid microextraction (SA-DLLME) using a surfactant as the disperser. This method is mainly used for the extraction of toxic organic pollutants by using surfactants below their critical micelle concentration (19-21).

Only two procedures have so far been reported for the extraction of inorganic trace metals from water samples. One, by Deng et al. (22) who reported a pre-concentration procedure for the determination of nickel in water samples 
using a pyridylazo naphthol chelating agent. They used the non-ionic Triton X-100 surfactant monomers as a disperser for the transfer of formed hydrophobic nickel chelate from aqueous phase into extracting carbon tetrachloride. Second, Yousefi et al. (18) reported the ion pair-based SA-DLLME for the extraction and pre-concentration of Cr(VI) from aqueous samples using the diphenylcarbazide chelating agent. An anionic sodium dodecyl sulfate monomer was used as an ion pair agent and dispersive agent and 1-octonal as an extracting solvent. To our knowledge, the ion pair-based surfactant-assisted microextraction procedure has never been reported before for the separation and pre-concentration of beryllium from natural water and wastewater samples without using a chelating agent.

This paper describes a new ion pair-based surfactant-assisted dispersive liquid-liquid microextraction (IP-SA-DLLME) procedure for the separation and pre-concentration of beryllium from drinking water, groundwater, and wastewater samples. A cetylpyridinium ammonium bromide (CPAB) was used as both ion pairing and dispersing solvent above its critical micelle concentration. Beryllium forms hydrophilic anionic species with oxalic acid, reacts with the cationic head group solubilizing sites of the CPAB aggregates, and forms a neutral ion-associate complex. It is then extracted from a bulk aqueous phase into a small volume of extracting chloroform. The parameters affecting the process were evaluated and optimized. The accuracy of the procedure was verified by analysis of certified reference materials (CRMs) such as NIST CRMs 1640, 1640a. and 1643e Trace Elements in Natural Water (National Institute of Technology, Gaithersburg, MD, USA).

\section{EXPERIMENTAL}

\section{Instrumentation}

Beryllium concentrations in the organic phases were determined by using a continuum source model Contra AA 700 electrothermal atomic absorption spectrometer (ETAAS) (Analytik Jena AG, Jena, Germany). A transversely heated graphite tube, MPE 60 autosampler and a xenon short arc lamp in hotspot mode, operated at $300 \mathrm{~W}$ as a continuum radiation source, were used. A high-resolution double monochromator consisting of a prism and an echelle grating monochromator, providing a spectral bandwidth per pixel of ca. 2 pm at $200 \mathrm{~nm}$, were used. A linear charge coupled device (CCD) array detector was used for measuring the integrated absorbance of beryllium at $234.8605 \mathrm{~nm}$. Argon with a purity of $99.99 \%$ was used as the purge gas. The optimized temperature program used for the determination of beryllium is listed in Table I. A magnetic stirrer (Tarson, Chennai, India) was used for mixing the solutions.

\section{Reagents and Standard Solutions}

Ultrapure water obtained from a Milli-Q ${ }^{\circledR}$ water purification system (Millipore Corporation, Bedford, MA, USA) was used to prepare all of the solutions. Sub-boiled $\mathrm{HNO}_{3}$ and

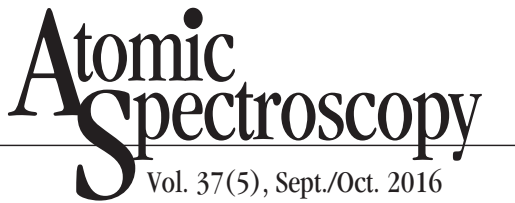

$\mathrm{HCl}$ acids (Merck, Darmstadt, Germany) were prepared in our laboratory using quartz stills kept inside the clean bench. A stock standard solution $\left(0.1 \mathrm{mg} \mathrm{mL}^{-1}\right)$ of beryllium was prepared using $1 \mathrm{mg} \mathrm{mL}^{-1}$ beryllium in 20\% $\mathrm{HCl}$ (Merck). Working standards were prepared daily by subsequent dilutions. The solutions of $10 \% \mathrm{~m} / \mathrm{v}$ cetylpyridinium ammonium bromide (CPAB), sodium dodecyl sulfate (SDS), cetyl trimethyl ammonium bromide (CTAB), and Triton X-114 were procured from SigmaAldrich, Steinheim, Germany, and prepared in water. A $1-\mathrm{mg} \mathrm{mL}^{-1}$ amount of $\mathrm{Pd}$ solution in $2 \% \mathrm{HNO}_{3}$ was taken from the $10-\mathrm{mg} \mathrm{mL}^{-1}$ stock solution (Sigma-Aldrich) and used as conventional modifier. The permanent $\mathrm{Zr}\left(5 \mathrm{mg} \mathrm{mL}^{-1}\right)$ solution was prepared from $\mathrm{ZrO}_{2}$ (Merck) by dissolving in $5 \mathrm{~mL} \mathrm{HNO}_{3}$ and $5 \mathrm{~mL} \mathrm{HF}$, and was made up to 100 $\mathrm{mL}$ volume using ultrapure water. The permanent $\mathrm{Zr}(50 \mu \mathrm{g})$ was coated onto the integrated platform of the standard pyrocoated tube as described in the literature (23). Sodium chloride (Merck) was used without further purificantion. The oxalic acid and chloroform, carbon tetrachloride, and trichloro ethylene were used directly without any further purification. An interference study was carried out by using $1 \mathrm{mg} \mathrm{mL}{ }^{-1}$ of $\mathrm{Ca}^{2+}, \mathrm{Mg}^{2+}, \mathrm{Al}^{3+}, \mathrm{Ni}^{2+}$, $\mathrm{Cd}^{2+}, \mathrm{Cu}^{2+}$, and $\mathrm{Z}^{\mathrm{n} 2}+$ solutions.

TABLE I

Optimized Temperature Program Used for the Determination of Be in Ion Pair-based Surfactant-assisted Dispersive Liquid-Liquid Microextraction Using ETAAS

\begin{tabular}{lcccc}
\hline Step & $\begin{array}{c}\text { Temperature } \\
\left({ }^{\circ} \mathrm{C}\right)\end{array}$ & $\begin{array}{c}\text { Ramp } \\
\left({ }^{\circ} \mathrm{C} \mathrm{s}^{-1}\right)\end{array}$ & $\begin{array}{c}\text { Hold } \\
(\mathrm{s})\end{array}$ & $\begin{array}{c}\text { Ar flow } \\
\left(\mathrm{mL} \mathrm{min}^{-1}\right)\end{array}$ \\
\hline Drying-1 & 60 & 6 & 10 & 250 \\
Drying-2 & 90 & 5 & 10 & 250 \\
Pyrolysis & 1500 & 300 & 10 & 250 \\
Gas adaption & 1500 & 0 & 5 & 250 \\
Atomization & 2300 & 2000 & 4 & 0 (read) \\
Cleaning & 2400 & 1500 & 3 & 250 \\
\hline
\end{tabular}


Drinking water, groundwater, and industrial effluent samples (from Be processing industry) were collected and named as effluent stage- 1 and stage-2. All of the samples were diluted 10 times, acidified with oxalic acid, and analyzed.

\section{Ion Pair-based SA-DLLME Procedure}

For the ion pair-based surfactantassisted dispersive liquid-liquid microextraction procedure, aliquots of 1-5 mL certified reference materials and water samples were taken in pre-cleaned sample vials containing a PTFE-coated stirrer bar and the acidity of the solution was maintained at $\mathrm{pH} 5$. Then, $1.25 \mathrm{~mL}$ of $10 \%(\mathrm{v} / \mathrm{v})$ oxalic acid, $0.4 \mathrm{~mL}$ of $10 \%(\mathrm{~m} / \mathrm{v})$ cetylpyridinium ammonium bromide, and $0.5 \mathrm{~mL}(\mathrm{v} / \mathrm{v})$ chloroform were added. These solutions were made up to $25 \mathrm{~mL}$ using Milli-Q ${ }^{\circledR}$ water (Millipore Corporation, USA). A cloudy solution was formed by the uniform dispersion of chloroform in the aqueous phase in the presence of the dispersive surfactant. The magnetic stirrer was turned on and the solution mixed for $10 \mathrm{~min}$ - utes at $300 \mathrm{rpm}$ to enhance the rate of the reaction between beryllium oxalate and the reactive solubilizing sites of the surfactant. After stirring, the fine droplets of the chloroform settled at the bottom of the sample vial. This chloroform layer was separated by removing the supernatant with a micropipette, and then an aliquot of $10 \mu \mathrm{L}$ was injected into the graphite tube for quantification of beryllium. A procedural blank was also prepared in the same manner.

\section{RESULTS AND DISCUSSION}

\section{Optimization of Ion Pair-based SA-DLLME Parameters}

The effects of each variable parameter in this dispersive liquidliquid microextraction process were studied by spiking the $50 \mathrm{pg}$ $\mathrm{mL}^{-1}$ beryllium to drinking, groundwater, and wastewater samples.

\section{Effect of Type and Concentra- tion of Acids}

Beryllium forms negatively charged hydrophilic complexes with oxalic acid and covalent and ionic compounds with hydrochlo- ric and nitric acids, respectively. Therefore, the type of acids and species formed and their interaction with the dispersive surfactant and extracting chloroform decides the recovery of beryllium. Hence, the effect of oxalic acid, along with common inorganic acids such as $\mathrm{HCl}$ and $\mathrm{HNO}_{3}$ at $0.5 \%(\mathrm{v} / \mathrm{v})$ concentration, on the relative absorbance signal of beryllium from drinking water was studied in the presence of $0.2 \%(\mathrm{v} / \mathrm{v}) \mathrm{CPAB}$ and $1 \mathrm{~mL}$ chloroform for selecting the appropriate stabilizing acid. The results shown in Figure 1 indicate that inorganic acids show a relatively low absorbance signal compared to organic acids. However, the relative absorbance signals of oxalic acid, $\mathrm{HCl}$, and $\mathrm{HNO}_{3}$ were 100,40 , and $20 \%$, respectively. Hence, oxalic acid was selected for further optimization of Be concentration.

The effects of oxalic acid on the recovery of beryllium in drinking and groundwater samples were studied in the concentration range of 0.1 to $2.0 \%(\mathrm{v} / \mathrm{v})$. The results in Figure 2 show the quantitative recovery $(97-100 \%)$ of beryllium in

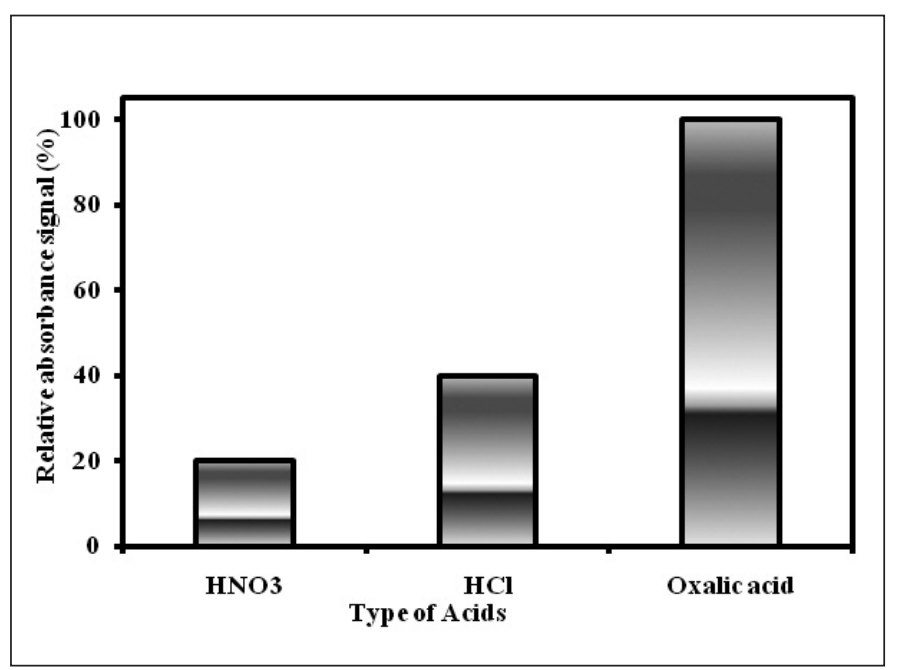

Fig. 1. Effect of type of acids such as $\mathrm{HNO}_{3}, \mathrm{HCl}$ and oxalic acids on the recovery of Be from drinking water using ion pair-based surfactant-assisted dispersive liquid-liquid microextraction in the presence of $0.2 \% v / v C P A B$ and $1 \mathrm{~mL}$ chloroform.

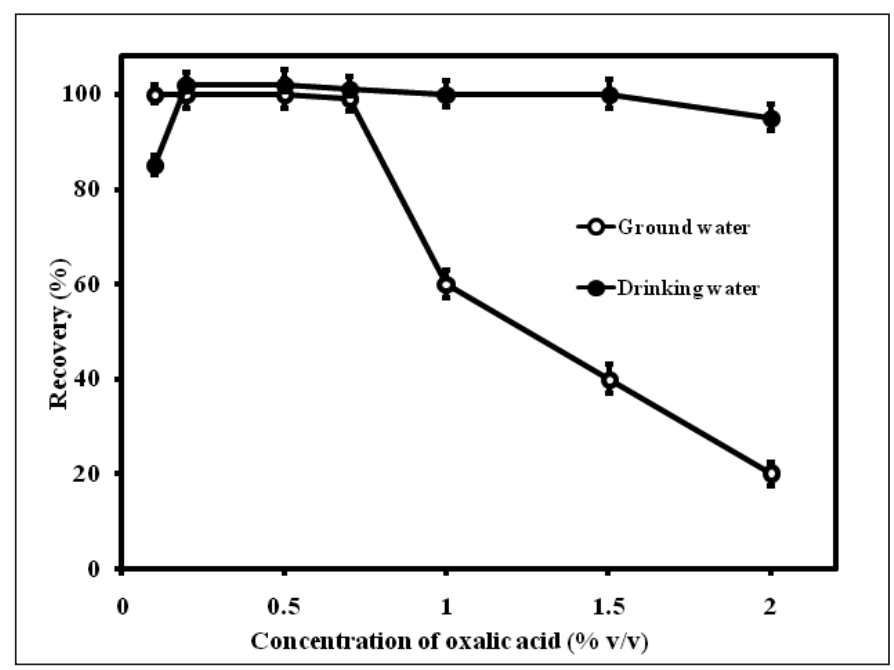

Fig. 2. Effect of oxalic acid concentration on the recovery of Be spiked to drinking water and groundwater samples in the presence of $0.2 \% v / v C P A B, p H 5$, and $1 \mathrm{~mL}$ chloroform. The error bars indicate the RSD (\%) of each measurement. 
the oxalic acid concentration range of 0.1 to $0.7 \%$ for both matrices; then the recovery decreased for groundwater, but remained constant for drinking water. Hence, a $0.5 \%$ oxalic acid concentration was selected for the extraction of beryllium.

\section{Effect of $\mathbf{p H}$}

In the extraction of metal ions, the complexing and extraction efficiencies are closely related to the $\mathrm{pH}$ of the solution. In order to obtain the desired complexing and pre-concentration efficiencies, the $\mathrm{pH}$ values were studied in the range of 1-6. The results indicated that the recovery of beryllium increased from $20 \%$ to $80 \%$ in the $\mathrm{pH}$ range of 1-4 and reaches a plateau beyond $\mathrm{pH} 4$. Hence, $\mathrm{pH} 5$ was selected for further studies.

\section{Mechanism of Be Extraction}

Beryllium reacts with oxalic acid and forms beryllium oxalate, $\mathrm{Be}\left(\mathrm{C}_{4} \mathrm{O}_{8}\right)^{2-}$. This oxalate ion forms a charge-neutral ion associated with $\mathrm{CPAB}$. The following equations indicate the reaction mechanism of beryllium extraction in the present procedure:

$$
\begin{aligned}
& \mathrm{Be}^{2+}+\mathrm{C}_{2} \mathrm{O}_{4} \mathrm{H}_{2} \rightarrow \mathrm{Be}\left(\mathrm{C}_{4} \mathrm{O}_{8}\right)^{2-} \\
& \mathrm{Be}\left(\mathrm{C}_{4} \mathrm{O}_{8}\right)^{2-}+\mathrm{C}_{21} \mathrm{H}_{38} \mathrm{NBr}+2 \mathrm{H}^{+} \rightarrow
\end{aligned}
$$$$
\mathrm{Be}\left(\mathrm{C}_{4} \mathrm{O}_{8}\right)^{2-} \cdot 2^{+} \mathrm{NH}_{38} \mathrm{C}_{21}+2 \mathrm{HBr}
$$

$\mathrm{Be}\left(\mathrm{C}_{4} \mathrm{O}_{8}\right)^{2-} \cdot 2^{+} \mathrm{NH}_{38} \mathrm{C}_{21}+\mathrm{CHCl}_{3} \rightarrow$ $\left(\mathrm{Be}\left(\mathrm{C}_{4} \mathrm{O} 8\right)^{2-} \cdot 2^{+} \mathrm{NH}_{38} \mathrm{C}_{21}\right) \cdot \mathrm{CHCl}_{3}$

where $\mathrm{Be}\left(\mathrm{C}_{4} \mathrm{O}_{8}\right)^{2-}$,

$\mathrm{Be}\left(\mathrm{C}_{4} \mathrm{O}_{8}\right)^{2-\cdot} 2^{+} \mathrm{NH}_{38} \mathrm{C}_{21}$, and $\left(\mathrm{Be}\left(\mathrm{C}_{4} \mathrm{O}_{8}\right)^{2-} \cdot 2^{+} \mathrm{NH}_{38} \mathrm{C}_{21}\right) \cdot \mathrm{CHC}_{13}$ are the beryllium oxalate, ion associate of beryllium oxalate with $\mathrm{CPAB}$, and extracted ion associate in chloroform, respectively.

\section{Effect of Type and Concentra- tion of Dispersive Surfactant}

Surfactants are amphiphilic molecules and form various aggregates that depend on volume and length of tails, and size and charge of head groups. These aggregates consist of various reactive hydrophobic, hydrophilic, and amphiphilic solubilizing sites (24). They quickly disperse in aqueous samples and interact effectively with targeted

\section{Atomic Apectroscopy \\ $\bigcup$ Vol. 37(5), Sept./Oct. 2016}

species using its reactive solubilizing sites. Therefore, various surfactants such as cationic cetyltrimethyl ammonium bromide (CTAB) and cetylpyridinium ammonium bromide (CPAB), anionic sodium dodecyl sulfate (SDS), and non-ionic Triton X-114 were prepared above their CMC and the effect on the recovery of hydrophilic beryllium oxalate in groundwater was studied. The results in Figure 3 show that the best recovery obtained was 75 and $95 \%$ with cationic surfactants $\mathrm{CTAB}$ and $\mathrm{CPAB}$, respectively. But, CPAB showed quantitative recovery when compared to $\mathrm{CTAB}$, which may be due to its high hydrophobic nature. The anionic surfactant SDS showed only $22 \%$ recovery, which may due to strong repulsive electrostatic interaction. However, the hydrophobic interaction of non-ionic Triton X-114 micelles was unable to extract any beryllium. Hence, the anionic CPAB surfactant was selected for further optimization of Be concentration.

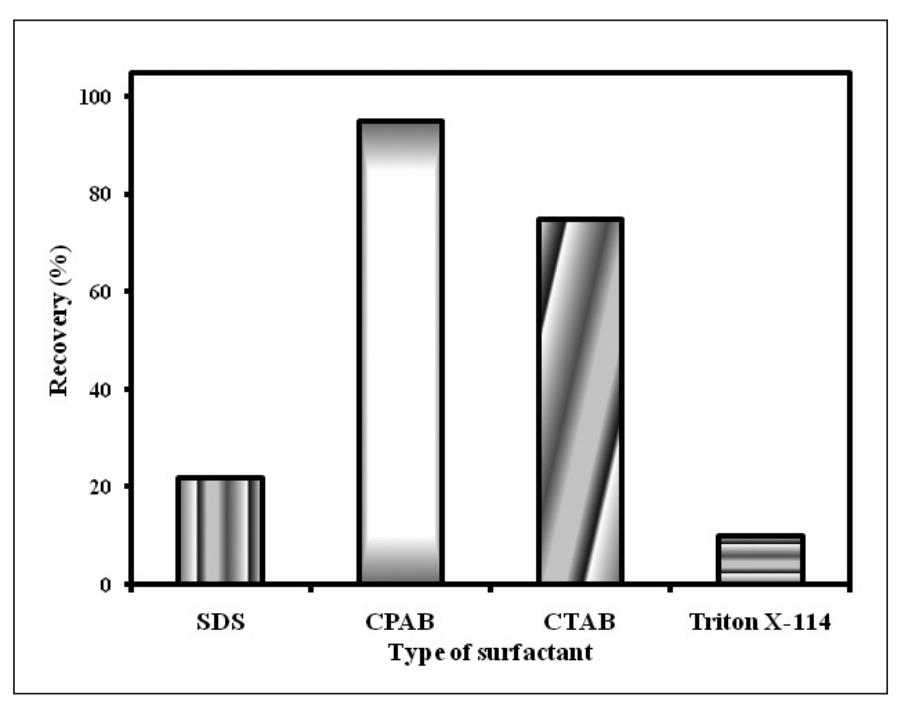

Fig. 3. Effect of surfactants such as sodium dodecyl sulfate (SDS), cetylpyridinium ammonium bromide (CPAB), cetyl trimethyl ammonium bromide (CTAB), and Triton $X-114$ on the recovery of Be in the presence of $0.5 \% v / v$ oxalic acid, $\mathrm{pH}$, and $1 \mathrm{~mL}$ chloroform.



Fig. 4. E ffect of CPAB concentration below and above the critical micelle concentrations (CMC) on the recovery of Be in drinking water and groundwater samples in the presence of $0.5 \% v / v$ oxalic acid, $p H 5$, and $1 \mathrm{~mL}$ chloroform. The error bars indicate the standard deviation at each measurements $(n=3)$. 
The concentration of $\mathrm{CPAB}$ was optimized in the range of $0.01-0.2 \%(\mathrm{v} / \mathrm{v})$ for drinking and groundwater samples. The results in Figure 4 show that good recovery was obtained in the aggregate interaction region when compared to the monomer interaction region. In the monomer interaction region of $0.01 \%$ to $0.026 \%$ (CMC), the monomers were responsible for extraction of beryllium where a maximum up to $30-45 \%$ recovery was obtained. Above the CMC, the recoveries increased and reached quantitative recoveries of $92-96 \%$ above the $0.1 \%$ CPAB. Hence, a concentration of $0.15 \%(\mathrm{v} / \mathrm{v}) \mathrm{CPAB}$ in the plateau region was selected.

\section{Effect of Type and Volume of Extraction Solvent}

The extraction solvent plays an important role in the separation and pre-concentration of the aggregate-stabilized beryllium oxalate from the aqueous phase. Therefore, the effect of $1 \mathrm{~mL}$ chloroform, carbon tetrachloride, and trichloro ethylene was studied. The results shown in Figure 5 show that chloroform has the highest extraction recovery compared to the other studied solvents. Therefore, chloro- form was selected and optimized between 0.1-1.5 mL. These results showed that in the range of $0.1-0.3$ $\mathrm{mL}$, the recovery increased from 60 to $90 \%$. It was found that up to the concentration range of $1.5 \mathrm{~mL}$, the recovery increased to $98 \%$. Hence, $0.5 \mathrm{~mL}$ of chloroform was selected as the extraction solvent.

\section{Effect of $\mathrm{NaCl}$}

The effect of electrolyte on the recovery of beryllium was briefly studied in the range of 1 to $10 \%$ $(\mathrm{m} / \mathrm{v}) \mathrm{NaCl}$ for drinking water. No significant effect was observed on the recoveries of beryllium within the studied range of $\mathrm{NaCl}$. This indicates that the presence of salt content below 10\% does not affect the performance of the present procedure.

\section{Effect of Stirring Rate and Extraction Time}

Stirring rate plays an important role on the rate of formation of beryllium oxalate and its subsequent transfer into an extraction solvent. Hence, the effect of stirring rates $(0,100,200,300$, and $400 \mathrm{rpm}$ ) using a magnetic stirrer on the recoveries of beryllium was studied by keeping the extraction

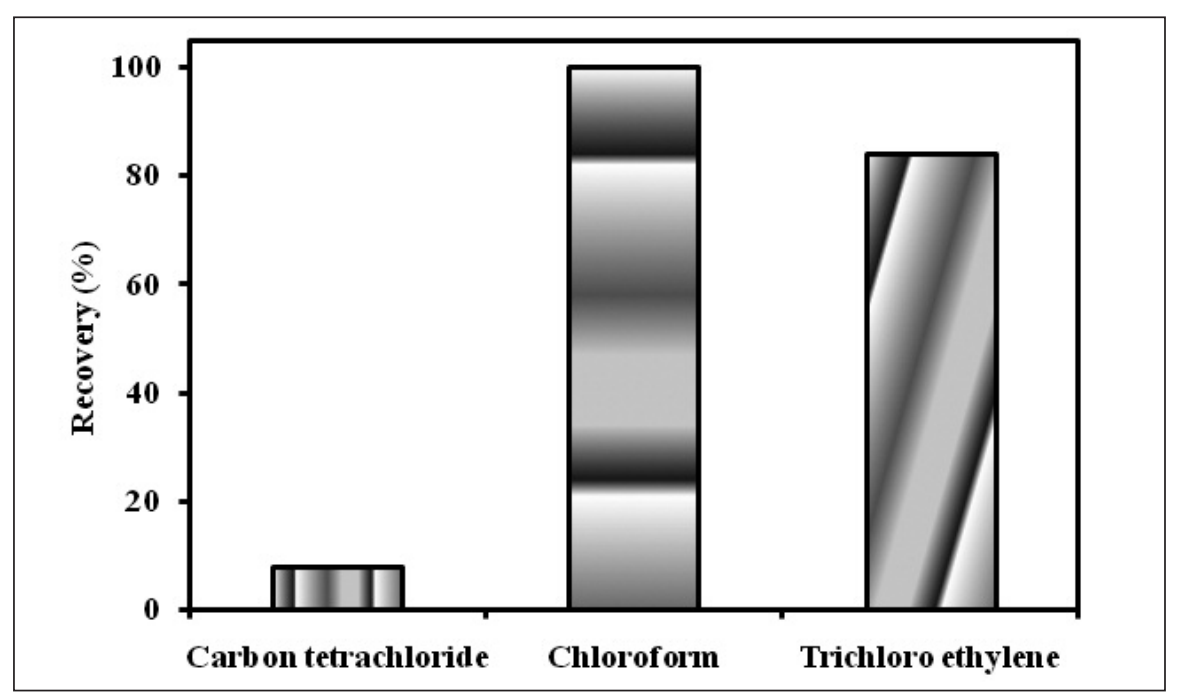

Fig. 5. Effect of various extraction solvents on the recovery of beryllium in the presence of $0.5 \% v / v$ oxalic acid, $p H 5$, and $0.15 \% v / v C P A B$. time constant (10 minutes). The results show that the recovery increased with an increase in the stirring rate up to $200 \mathrm{rpm}$ and remained constant up to $800 \mathrm{rpm}$. Thus, the optimum stirring rate of $300 \mathrm{rpm}$ was selected.

The effect of the extraction time on the recovery of beryllium was studied in the range of $0-15$ minutes by keeping all other parameters constant. The results showed that there was no significant difference between the different extraction times above 5 minutes. This is mainly due to the fast dispersion of the fine droplets of the surfactant in both the aqueous phase and the organic chloroform phase. Hence, the extraction time of 10 minutes was selected.

\section{Interferences and Recovery Studies}

In order to evaluate the performance of the present optimized procedure for various natural environmental matrices, the highest tolerability of the various common interfering ions was studied. Interferences may occur because of the competition of other metal ions to form ion-associates with the dispersing surfactant and also with anionic beryllium oxalate. The highest tolerability limits of various foreign ions spiked with $50 \mathrm{pg} \mathrm{mL}^{-1}$ of beryllium and by keeping the relative error between $\pm 5 \%$ were found to be $50 \mathrm{mg} \mathrm{L}^{-1}$ of $\mathrm{Mg}^{2+}, 40 \mathrm{mg} \mathrm{L}^{-1}$ of $\mathrm{Ca}^{2+}, 8 \mathrm{mg} \mathrm{L}^{-1}$ of $\mathrm{Cu}^{2+}, \mathrm{Mn}^{2+}$ and $\mathrm{Pb}^{2+}, 4 \mathrm{mg} \mathrm{L}^{-1}$ of $\mathrm{Fe}^{3+}, 1 \mathrm{mg} \mathrm{L}^{-1}$ of $\mathrm{Cr}^{6+}$, and $50 \mathrm{mg} \mathrm{L}^{-1}$ of $\mathrm{SO}_{4}{ }^{2-}$ and $\mathrm{PO}_{4}{ }^{3-}$ for the proposed procedure. These results demonstrated the high selectivity of the proposed process for the extraction of beryllium.

\section{Optimization of Furnace Temperature Program}

The effect of pyrolysis and atomization temperature on the absorbance signal of $10 \mathrm{pg} \mathrm{mL}^{-1}$ of beryllium extracted into the 
extracting chloroform was studied by using a pyrocoated standard tube with a conventional Pd- and permanent $\mathrm{Zr}$-coated tube. The results in Figure 6 indicate that the permanent $\mathrm{Zr}$-coated tube shows compared to the standard pyrocoated tube with the Pd modifier. In both tubes, the absorbance increased initially between 900 and $1100{ }^{\circ} \mathrm{C}$, then reached a plateau up to a pyrolysis temperature of 1400 and $1500^{\circ} \mathrm{C}$, respectively, for the standard pyrocoated and permanent $\mathrm{Zr}$-coated tube. Beyond $1400{ }^{\circ} \mathrm{C}$, there is a loss of beryllium with the standard coated tube.

Hence, a pyrolysis temperature of $1400^{\circ} \mathrm{C}$ was selected for the permanent Zr-coated tube. Optimization of the atomization tempera2000-2400 ${ }^{\circ} \mathrm{C}$ for both tubes. The atomization signal increased with an increase in the atomization temperature from 2000 to $2200{ }^{\circ} \mathrm{C}$ and stabilizes around $2300{ }^{\circ} \mathrm{C}$ in both cases. Hence, the $\mathrm{Zr}$-coated tube was selected with a $2300{ }^{\circ} \mathrm{C}$ atomization temperature. an improved absorbance signal ture was carried out in the range of

\section{Analytical Figures of Merit}

Under the optimized experimental conditions, the calibration curve was obtained by pre-concentrating the successively spiked standards of the beryllium in the range of 20-500 $\mathrm{pg} \mathrm{mL}^{-1}$ for a drinking water sample. The correlation coefficient was 0.9896. Quantifications of beryllium in drinking water, groundwater, and wastewater samples were performed using the aqueous calibration graph. The preconcentration factor is the ratio of the analyte concentration in the final chloroform layer to that of the initial aqueous phase. Under the optimized conditions, the pre-concentration factor was 25 . The limit of detection, calculated based on three times the standard deviation of 10 measurements of the procedural blanks, was $1 \mathrm{pg} \mathrm{mL} \mathrm{mL}^{-1}$. A characteristic mass $\left(\mathrm{m}_{\mathrm{o}}\right)$ of $0.25 \mathrm{pg}$ was obtained by measuring the integrated absorbance signal on the $\mathrm{Zr}$ coated tube, which is better than the reported value where a tungsten platform kept in a pyrolytically coated tube with zirconium as a chemical modifier was used (25). The advantages of the proposed procedure were comparable with

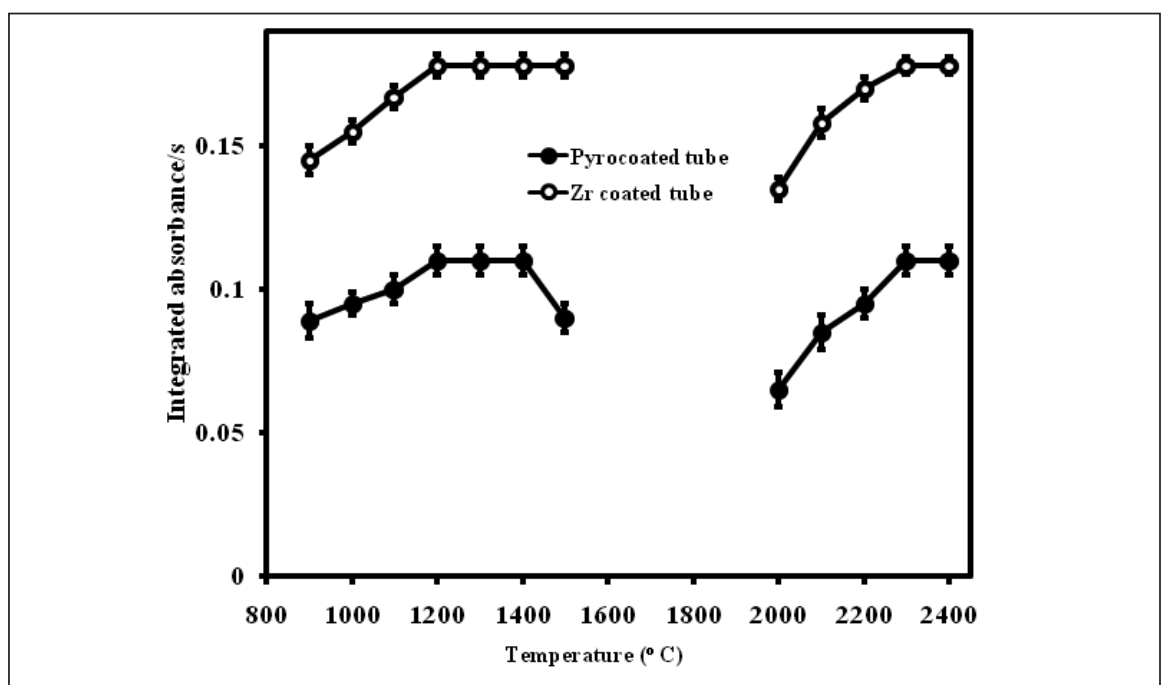

Fig. 6. Effect of pyrolysis and atomization temperature on the absorbance of $10 \mathrm{pg}$ $m L^{-1}$ of Be extracted into the extracting solvent chloroform in the present procedure with pyrocoated tube (standard tube with Pd-modifier) and Zr-coated tubes.

\section{Atomic Apectroscopy 1 Vol. 37(5), Sept./Oct. 2016}

the recently published pre-concentration and procedures as given in Table II $(9-13,15,26)$. It clearly shows the utility of surfactant aggregates for the extraction of beryllium by acting as an ion-pairing agent as well as a dispersing agent. It also avoids the use of a heating step commonly used in cloud point extraction, and provides fast extraction compared to reported micelle and mixed micelle cloud point extraction procedures.

\section{Applications}

In order to evaluate the analytical applicability of the present optimized procedure to effluents and natural water samples, the recovery studies were performed by spiking the beryllium in the range of 50-250 $\mathrm{pg} \mathrm{mL}^{-1}$. The recoveries, listed in Table III, were in the range of $92-98 \%$ in the studied concentration range with a $3-10 \%$ relative standard deviation. These results show that the proposed method can be applied successfully to the separation, recovery, and determination of ultratrace levels of beryllium in effluents and water samples.

The accuracy of the proposed procedure was verified by analyzing certified reference materials NIST CRM 1640, 1640a and 1643e Trace Elements in Natural Water. As can be seen in Table IV, the values obtained were in good agreement with the certified values based on the student's $t$-test at the 95\% confidence level. The beryllium concentration obtained by the present procedure in certified reference materials was compared with the results obtained by a reported CPE procedure using the chelating agent (10). These values show that there is a good agreement of results obtained by both procedures.

\section{CONCLUSION}

The described procedure provides a new ion pair-based surfac- 
TABLE II

Comparison of Analytical Figures of Merit of Proposed Procedure With Various Reported Pre-concentration Procedures

\begin{tabular}{|c|c|c|c|c|}
\hline $\begin{array}{l}\text { Pre-conc./ } \\
\text { Analytical } \\
\text { Method }\end{array}$ & $\begin{array}{l}\text { Chelating Agent } \\
\text { Surfactant }\end{array}$ & $\begin{array}{l}\text { Condition } \\
\text { (Temp. }{ }^{\circ} \mathrm{C} / \\
\text { Time. min.) }\end{array}$ & $\begin{array}{c}\mathrm{LOD} \\
\left(\mathrm{mL}^{-1}\right) / \\
\mathrm{PCF}\end{array}$ & Ref. \\
\hline CPE - SP & $\begin{array}{l}\text { Chrome Azurol S/ } \\
\text { CTAB + KI }\end{array}$ & $\mathrm{RT} / 15$ & $500 / 20$ & (9) \\
\hline CPE - ETAAS & Cupferron/Triton X-114 & $60 / 35$ & $20 / 20$ & $(10)$ \\
\hline MM - CPE-SPa & $\begin{array}{l}\text { Chrome Azurol S/ } \\
\text { CPAC }^{\mathrm{e}}+\text { Triton X-114 }\end{array}$ & $50 / 20$ & $50 / 25$ & $(11)$ \\
\hline MM - CPE-ICP-AES ${ }^{\mathrm{b}}$ & $\begin{array}{l}\text { 1,8-dihydroxyanthrone/ } \\
\text { CPAC }^{\mathrm{e}}+\text { Triton X-114 }\end{array}$ & $50 / 20$ & $1 / 16.7$ & $(12)$ \\
\hline MM - CPE-SP & $\begin{array}{l}\text { Chrome Azurol S/ } \\
\text { CTAB }^{\text {f }}+\text { Triton X-114 }\end{array}$ & $\mathrm{RT} / 5$ & $980 / 20$ & (13) \\
\hline SPE - ICP-MS & Silica Gel/EDTA & $\mathrm{RT} / 90$ & $0.0036 / 170$ & (15) \\
\hline SPE $^{c}$ - ETAAS & Acetyl Acetone/C18 & $\mathrm{RT} / 60$ & $2 /-$ & (26) \\
\hline $\begin{array}{l}\text { IP-SA - DLLME- } \\
\text { ETAAS }^{\mathrm{d}}\end{array}$ & $\begin{array}{l}\text { Oxalic Acid/CPAB + } \\
\text { Chloroform }\end{array}$ & $\mathrm{RT} / 10$ & $\begin{array}{r}\mathrm{P} \\
\text { Pro }\end{array}$ & $\begin{array}{r}\text { Present } \\
\text { Procedure }\end{array}$ \\
\hline $\begin{aligned} & \mathrm{a}= \text { Mixed micelle-c } \mathrm{c} \\
& \mathrm{b}= \text { Mixed micelle- } \mathrm{c} \\
& \text { emission spect } \\
& \mathrm{c}= \text { Solid phase ext } \\
& \mathrm{d}= \text { Ion pair based } \mathrm{s} \\
& \text { electrothermal } \\
& \mathrm{e}= \text { Cetyl pyridyl an } \\
& \mathrm{f}\end{aligned}$ & $\begin{array}{l}\text { point extraction-induc } \\
\text { try. } \\
\text { on. } \\
\text { ctant assisted dispersive } \\
\text { ic absorption spectrom } \\
\text { nium chloride. }\end{array}$ & ly couple & $\begin{array}{l}\text { sma-atomic } \\
\text { roextractior }\end{array}$ & \\
\hline
\end{tabular}

TABLE III

Recovery of Be From Various Water and Effluent Samples Using Proposed Procedure

\begin{tabular}{|c|c|c|c|}
\hline Matrices & $\begin{array}{l}\text { Spiked } \\
\left(\mathrm{pg} \mathrm{mL}^{-1}\right)\end{array}$ & $\begin{array}{c}\text { Found }) \\
\left(\text { ng mL } \mathrm{mL}^{-1}\right) \\
(\text { mean } \pm \mathrm{SD})^{\mathrm{a}}\end{array}$ & $\begin{array}{l}\text { Recovery (\%) } \\
\left(\mathrm{ng} \mathrm{mL} \mathrm{mL}^{-1}\right)\end{array}$ \\
\hline \multirow[t]{4}{*}{ Drinking Water } & 0 & $\mathrm{Nd}^{\mathrm{b}}$ & - \\
\hline & 50 & $45 \pm 3$ & $90 \pm 6$ \\
\hline & 100 & $96 \pm 4$ & $96 \pm 4$ \\
\hline & 250 & $242 \pm 7$ & $97 \pm 3$ \\
\hline \multirow[t]{3}{*}{ Ground Water } & 0 & $\mathrm{ND}^{\mathrm{b}}$ & - \\
\hline & 50 & $44 \pm 4$ & $88 \pm 8$ \\
\hline & 250 & $92 \pm 5$ & $92 \pm 5$ \\
\hline \multirow[t]{3}{*}{ Effluent Stage-1 } & 0 & $48.0 \pm 0.5$ & - \\
\hline & 100 & $98 \pm 8$ & $98 \pm 8$ \\
\hline & 250 & $240 \pm 10$ & $96 \pm 4$ \\
\hline \multirow[t]{3}{*}{ Effluent Stage-2 } & 0 & $10.8 \pm 0.3$ & - \\
\hline & 50 & $47 \pm 5$ & $94 \pm 10$ \\
\hline & 250 & $240 \pm 10$ & $96 \pm 4$ \\
\hline
\end{tabular}

$\mathrm{a}=$ Mean of four determinations \pm standard deviation.

,${ }^{\mathrm{b}}=$ Not detected. tant-assisted dispersive liquid-liquid microextraction (IP-SA-DLLME) procedure for the simultaneous separation and pre-concentration of beryllium prior to its determination by ETAAS. This procedure was carried out at room temperature and does not use any special type of chelating agents; hence, it is more energy efficient and can be applied to the removal of beryllium at the sampling site itself. This procedure is very useful for establishing the background levels of beryllium in and around the beryllium treatment plants and also to remove/recover high levels of beryllium from effluent samples to control environmental contamination.

Received January 17, 2016.

Revision received Aprl 22, 2016.

\section{REFERENCES}

1. R. G. Cooper and A. P. Harrison, Indian J. Occup. Environ Med. 13(2), 65 (2009).

2. D. K. Verma, A. C. Ritchie and M. L. Shaw, Occup. Medicine 53, 223 (2003).

3. W. T. Sanderson, E. M. Ward, K. Steenland and M. R. Petersen, Am. J. Ind. Med. 39, 123 (2001).

4. M. K. S. Berigan, J. A. Deddens, J. R. Couch and M. R. Petersen, Occup. Environ. Med. 68, 354 (2011).

5. T. A. Tomberlin, INEEL/Con-0401869(2014), Available at: http://citeseerx.ist.psu.edu/viewd oc/download?doi=10.1.1.543.4019 $\&$ rep=rep $1 \&$ type $=$ pdf.

6. M. J. Brisson, K. Ashley, A. B. Stefaniak, A. A. Ekechukwu and K. L. Creek, J. Environ. Monit. 8, 605 (2006).

7. J. L. Burguera, M. Burguera, C. Rondon, P. Carrero, M. R. Brunetto and Y. P. Pena, Talanta 52, 27 (2000).

8. H. W. Peng and M. S. Kuo, Anal. Sci. 16, 157 (2000). 


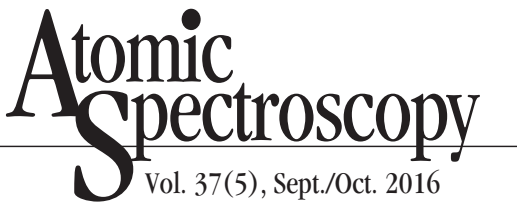

TABLE IV

Analytical Results for the Determination of Be in CRMs Using the Proposed Procedure

\begin{tabular}{|c|c|c|c|}
\hline CRMs & $\begin{array}{r}\text { Measu } \\
\left(\mathrm{ng} \mathrm{g}^{-1}\right)(\mathrm{me} \\
\text { IP-SA- } \\
\text { DLLME }\end{array}$ & $\begin{array}{l}\text { ured Value } \\
\left.\text { ean } \pm^{\mathrm{a}} \text { ts }(\mathrm{n})^{-1 / 2}\right) \\
\text { Micelle-based } \\
\text { CPE }^{\mathrm{b}}\end{array}$ & $\begin{array}{c}\text { Certified } \\
\text { Value }\left(\mathrm{ng} \mathrm{g}^{-1}\right)\end{array}$ \\
\hline $\begin{array}{l}\text { NIST } 1640 \\
\text { Trace Elements in Natural Water }\end{array}$ & $34.92 \pm 0.38$ & $34.66 \pm 0.56$ & $34.94 \pm 0.41$ \\
\hline $\begin{array}{l}\text { NIST } 1640 \mathrm{a} \\
\text { Trace Elements in Natural Water }\end{array}$ & $3.00 \pm 0.10$ & $3.00 \pm 0.15$ & $3.002 \pm 0.027$ \\
\hline $\begin{array}{l}\text { NIST } 1643 \mathrm{c} \\
\text { Trace Elements in Natural Water }\end{array}$ & $13.62 \pm 0.11$ & $13.75 \pm 0.15$ & $13.64 \pm 0.16$ \\
\hline
\end{tabular}

$\mathrm{a}=\mathrm{t}_{0.95}=3.18, \mathrm{n}=4$ and $\mathrm{s}=$ standard deviation.

$\mathrm{b}=$ Values are obtained from non-ionic based CPE procedure with chelating agent Ref. 10.

9. A. Afkhami, T. Madrakian, E. Bozorgzadeh and $\mathrm{M}$. Bahram,Talanta 71,1103 (2007).

10. L. Machackova and M. Zemberyova, Anal. Methods 4, 4042 (2012).

11. A. Beiraghi,A. R. Zarei and $\mathrm{S}$. Babaee, Anal. Sci. 23, 527 (2007).

12. A. Beiraghi and S. Babaee, Anal. Chim. Acta 607, 183 (2008).

13. M. Bahram,T. Madrakian, E. Bozorgzadeh and A. Afkhami, Talanta 72, 408 (2007).

14. J. J. Charlton, N. C Jones, R. A. Wallace, R. W. Smithwick, J. A. Bradshaw, I. I. Kravchenko, N. V. Lavrik and M. J. Sepaniak, Anal. Chem. 2015. DOI:10.1021/ acs.analchem.5b0103.

15. H. Tazoe, T. Yamagata, H. Obata and H. Nagai, Anal. Chim. Acta 852, 74 (2014).

16. P. P. Francisco, I. Lavilla and C. Bendicho, Spectrochim. Acta, Part B 64, 1 (2009).

17. H. M. A. Saidi and A. A. A. Emara, J. Saudi Chem. Soc 18, 745 (2014).

18. S. M. Yousefi and F. Shemirani, J. Harad. Mater. 254-255, 134 (2013).

19. M. Moradi, Y. Yamini, A. Esrafili and S. Seidi,Talanta 82, 1864 (2010).

20. J. Chenga, Y. Xia, Y. Zhou, F. Guo and G. Chen, Anal. Chem. Acta 701, 86 (2011).
21. M. Behbahani, F. Najafi, S. Bagheri, M. K. Bojdi, M. Salarian and A. Bagheri, J. Chromatogr. A 1308, 25 (2013).

22. Q. Deng, M. Chen, L. Kong, X. Zhao, J. Guo and X. Wen, Spectrochim. Acta, Part A 104, 64 (2013).

23. E. C. Lima, F. J. Krug and K. W. Jackson, Spectrochim. Acta, Part B 53, 1791 (1998).

24. S. Segota and D. Tezak, Adv. Colloid Interface Sci. 121, 51 (2006).

25. M. A. Castroa, L. C. Roblesa, J. M. Lumbrerasa, B. de Celis, A. J. Aller, and D. Littlejohn, Anal. Chem. Acta 636, 158 (2009).

26. H. W. Peng and M. S. Kuo, Anal. Sci. 16, 157 (2000). 